\title{
Correction to: Commentary: Excavating the Intimate
}

\author{
Stacey Lynn Camp
}

Published online: 12 October 2018

C Society for Historical Archaeology 2018

\section{Correction to: Hist Arch}

https://doi.org/10.1007/s41636-018-

\section{3-8}

The last sentence in the 1 st paragraph on page 5 should read:

Importantly, this incident raises the question of how we avoid making our objects of study - some of whom have lived through the trauma of incarceration and are now being forced to relive it-feel objectified.

The last sentence in the 1st paragraph on page 6 should read:

Some archaeologists have already begun exploring how certain vectors of identity - such as regional affil- iation, place of migration, age, and gender-shaped material practices, such as landscaping, gardening, and prisoners' choice of goods (Kamp-Whittaker 2010; Shew 2010; Shew and Kamp-Whittaker 2013; Ng 2014).

The 5 th sentence in the 2 nd paragraph on page 6 should read:

For these reasons and many others (many of which hinge on contemporary debates regarding citizenship [Camp 2013]), speaking about the archaeology of internment can lead to public threats, as well as subtle and not-so-subtle comments from colleagues that "real" archaeology is found in the much deeper past.

The online version of the original article can be found at https://doi.org/10.1007/s41636-018-0133-8

S. L. Camp $(\bowtie)$

Department of Anthropology, Michigan State University, 655

Auditorium Drive, East Lansing, MI 48824, U.S.A.

e-mail: campstac@msu.edu 